\title{
Rare-earth sulfides nanocrystals from wet colloidal synthesis: tunable compositions, size-dependent light absorption and sensitized rare-earth luminescence
}

\author{
Guillaume Gouget, ${ }^{\dagger}$ Morgane Pellerin, ${ }^{\ddagger}$ Rabih Al Rahal Al Orabi, ${ }^{\nabla}$ Lauriane \\ Pautrot-D'Alençon, ${ }^{\ddagger}$ Thierry Le Mercier, $\stackrel{\ddagger}{\ddagger}$ and Christopher B. Murray ${ }^{*}, \dagger$ \\ 'Department of Chemistry, University of Pennsylvania, Philadelphia, Pennsylvania 19104, United States \\ "Solvay, Research and Innovation Center Paris, F-93308, Aubervilliers, France \\ ${ }^{\nabla}$ Solvay, Design and Development of Functional Materials Department, Axel'One, 87 avenue des Frères Perret, \\ 69192 Saint Fons, Cedex, France
}

Experimental section

Structural Characterization

Optical characterizations

Figure S1. Phase diagrams of bulk lanthanum and europium sulfides.

Figure S2. Structural characterization of europium sulfide NCs.

Figure S3. Absorption spectrum of EuS NCs.

Figure S4. Size distribution of $\mathrm{La}_{2} \mathrm{~S}_{3}$ and $\mathrm{La}_{2} \mathrm{~S}_{3}: \mathrm{Er}^{3+}(10 \%) \mathrm{NCs}$.

Figure S5. Structural and optical characterization of $\mathrm{La}_{2} \mathrm{~S}_{3}: \mathrm{Sm}^{3+}(10 \%)$.

Figure S6. Absorption spectra of $\mathrm{La}_{2} \mathrm{~S}_{3}$ and $\mathrm{La}_{2} \mathrm{~S}_{3}: \mathrm{Er}^{3+}(10 \%) \mathrm{NCs}$. 8

Figure S7. Tauc plot of suspended $\mathrm{La}_{2} \mathrm{~S}_{3} \mathrm{NCS}$. 8

Figure S8. Luminescence of $\mathrm{La}_{2} \mathrm{~S}_{3}$ and $\mathrm{La}_{2} \mathrm{~S}_{3}: \mathrm{Er}^{3+}(10 \%) \mathrm{NCs}$. 9

Figure S9. Energy diagram of $\mathrm{Er}^{3+} 4 \mathrm{f}$ levels with spin-orbit splitting. 9

Figure S10. Le Bail refinement of $\mathrm{LaS}_{2}$ ellipsoidal NCs. 10

Figure S11. Size distribution of $\mathrm{LaS}_{2} \mathrm{NCs}$. 11

Figure S12. SAED of LaS $\mathrm{NCs}$. 12

Figure S13. HRTEM pictures of $11.6 \times 4.4 \mathrm{~nm}^{2}$ LaS $_{2}$ nanoplates. 13

Figure S14. Total and elemental mass balances from the synthesis of $\mathrm{LaS}_{2}$ nanoplates. 14

Figure S15. XRD diagram of the precipitate recovered from the dissolution of $\mathrm{Lal}_{3}$ in OLA. $\quad 15$

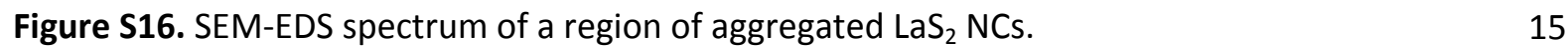

Figure S17. $\mathrm{LaOBr}^{-\mathrm{LaS}_{2}}$ mixture from $\mathrm{LaBr}_{3}$ and $\mathrm{S}^{(0)}$ in OLA at $330^{\circ} \mathrm{C}$ during $1 \mathrm{~h}$. 15

Figure S18. Total and elemental mass balances from the synthesis of $5.9 \mathrm{~nm}$ EuS NCs. 16

Figure S19. Calculated density of states of bulk $\mathrm{LaS}_{2}$.

Figure S20. Structural characterization of $\mathrm{GdS}_{2} \mathrm{NCs}_{\text {from } \mathrm{Gdl}_{3} \text {. }} \quad 17$

Figure S21. Structural characterization of $\mathrm{Sm}_{2} \mathrm{~S}_{3} \mathrm{NCs}$ from $\mathrm{Sml}_{2}$. 18

Figure S22. Stability of lanthanum sulfide NCs upon exposure to air. $\quad 18$

References $\quad 19$ 


\section{Experimental section}

Materials and chemicals. Europium diiodide (Eul ${ }_{2}$, Sigma-Aldrich, $99.9 \%$ ), lanthanum triiodide ( Lal $_{3}$, Alfa Aesar, 99.9\%), erbium triiodide ( $\mathrm{Erl}_{3}$, Alfa Aesar, $\left.99.9 \%\right)$, samarium triiodide $\left(\mathrm{Sml}_{3}\right.$, SigmaAldrich, $99.9 \%)$ elemental sulfur ( $S^{(0)}$, Sigma-Aldrich, $\left.99.998 \%\right)$ and (bis-trimethylsilyl)sulfide $\left((\mathrm{TMS})_{2} \mathrm{~S}\right.$, Sigma-Aldrich, synthesis grade) are stored in a nitrogen-filled glovebox. Sulfur flakes and rare-earth iodide beads are ground using a mortar before use. Oleylamine (OLA, Sigma-Aldrich, $70 \%$ ) is vacuum-dried on a Schlenk line during $4 \mathrm{~h}$ at $120^{\circ} \mathrm{C}$ before being transferred in a glovebox. A (TMS) ${ }_{2} \mathrm{~S}-\mathrm{OLA}$ stock solution is prepared by mixing $1.257 \mathrm{~g}$ of $(\mathrm{TMS})_{2} \mathrm{~S}$ with $3.069 \mathrm{~g}$ of vacuum-dried OLA. Toluene, tetrachloroethylene (TCE) and acetonitrile (MeCN) are ACS grade from Fisher.

Synthesis of EuS. From $\mathbf{S}^{(0)}$ : In the glovebox, $\mathbf{S}^{(0)}(160 \mathrm{mg}, 5.00 \mathrm{mmol})$ is mixed in vacuum-dried OLA $\left(10 \mathrm{~mL}\right.$ ) at $45^{\circ} \mathrm{C}$ during until it fully dissolves (approx. $1 \mathrm{~h}$ ), yielding a red solution (OLA-S). Eul 2 (203 mg, $0.50 \mathrm{mmol}$ ) and OLA-S are added at RT in a $125 \mathrm{~mL}$ three-neck flask. The solution darkens within seconds. The reactant medium is transferred from the glovebox to a Schlenk line and it is heated to $220^{\circ} \mathrm{C}$ during $1 \mathrm{~h}$, using a heating mantle. The deep purple dispersion is then cooled down to $70{ }^{\circ} \mathrm{C}$ by blowing cool air. Precipitation occurs as the temperature of the medium decreases. The suspension is diluted with $10 \mathrm{~mL}$ of toluene and centrifuged at $8900 \mathrm{~g}$ during $3 \mathrm{~min}$. The orange supernatant is discarded. The pellet is dispersed in TCE $(10 \mathrm{~mL})$ and reprecipitated in MeCN $(7.5 \mathrm{~mL})$, the suspension is centrifuged and the pellet is separated from the supernatant. This purification step is repeated once. The pellet is dispersed in TCE, yielding a deep purple dispersion. From (TMS) $\mathbf{S}$ : In the glovebox, $\mathrm{Eul}_{2}(101 \mathrm{mg}, 0.25 \mathrm{mmol})$ is mixed in vacuum-dried OLA $(10 \mathrm{~mL})$ at approx. $130^{\circ} \mathrm{C}$ during approx. 30 min until $\mathrm{Eul}_{2}$ is fully dissolved (bright yellow solution). The rare-earth-containing solution is left to cool and then transferred to a $125 \mathrm{~mL}$ three-neck glass flask connected to a Schlenk line under $\mathrm{N}_{2}$. The reactant medium is heated to $150{ }^{\circ} \mathrm{C}$ using a heating mantle. When the temperature is stabilized, 180 or $130 \mu \mathrm{L}$ of (TMS) $)_{2} \mathrm{~S}$-OLA stock solution $\left(0.35\right.$ or $0.25 \mathrm{mmol}$ of (TMS) ${ }_{2} \mathrm{~S}$, respectively) is injected with a syringe in the reactant medium under vigorous stirring. The yellow solution immediately turns dark. The temperature is maintained $10 \mathrm{~min}$ at $150^{\circ} \mathrm{C}$ and it is then dropped to $70^{\circ} \mathrm{C}$ by removing the heating mantle and blowing cool air. The purple-red dispersion is diluted with toluene $(10 \mathrm{~mL})$ and precipitated with $\mathrm{MeCN}(7.5 \mathrm{~mL})$. The suspension is centrifuged at $8900 \mathrm{~g}$ during $3 \mathrm{~min}$, resulting in a clear yellow supernatant, which is discarded. The pellet is redispersed $(7.5 \mathrm{~mL})$ in toluene and then reprecipitated using $\mathrm{MeCN}(4 \mathrm{~mL})$. After centrifugation at $8900 \mathrm{~g}$ during $3 \mathrm{~min}$, the clear colorless supernatant is discarded, while the pellet is redispersed in toluene, leading to a deeply colored purple-red solution.

Synthesis of $\mathrm{La}_{2} \mathrm{~S}_{3}$. In the glovebox, $\mathrm{Lal}_{3}(260 \mathrm{mg}, 0.50 \mathrm{mmol})$ is mixed in vacuum-dried OLA $(10 \mathrm{~mL})$ at $45^{\circ} \mathrm{C}$ until $\mathrm{Lal}_{3}$ is dissolved (approx. $1 \mathrm{~h}$ ), leading to a pale yellow solution which is slightly cloudy. Centrifugation at $8900 \mathrm{~g}$ during $3 \mathrm{~min}$ enables separating a white solid from the solution. The solution is transferred to a $125 \mathrm{~mL}$ three-neck flask connected to a Schlenk line under $\mathrm{N}_{2}$. The reactant medium is heated to $220^{\circ} \mathrm{C}$ using a heating mantle. When the temperature is stabilized, $470 \mu \mathrm{L}$ of (TMS) $)_{2} \mathrm{~S}-\mathrm{OLA}$ stock solution $\left(0.91 \mathrm{mmol}\right.$ of $\left.(\mathrm{TMS})_{2} \mathrm{~S}\right)$ is injected with a syringe in the reactant medium under vigorous stirring. The solution turns bright yellow within minutes. The temperature is maintained $1 \mathrm{~h}$ and it is then is dropped to $120^{\circ} \mathrm{C}$ in 2-3 min by removing the heating mantle and blowing cool air. At $70^{\circ} \mathrm{C}$, the yellow dispersion is diluted in toluene $(10 \mathrm{~mL})$. Addition of MeCN $(7.5 \mathrm{~mL})$ leads to the strong precipitation of a creamy white solid. The dispersion is centrifuged at $8900 \mathrm{~g}$ during $3 \mathrm{~min}$. The clear transparent supernatant is discarded, while the pellet is dispersed in toluene, precipitated using $\mathrm{MeCN}$, and centrifuged at $8900 \mathrm{~g}$ during $3 \mathrm{~min}$. The purification is 
performed twice, yielding a yellow suspension. The synthesis is adapted by using several rare-earth iodides with various proportions introduced at the beginning of the protocol: (i) $\mathrm{Lal}_{3}$ ( $234 \mathrm{mg}$, $0.45 \mathrm{mmol}$ ) and ( $\left.\mathrm{Erl}_{3} 27 \mathrm{mg}, 0.05 \mathrm{mmol}\right)$, or (ii) $\mathrm{Lal}_{3}\left(234 \mathrm{mg}, 0.45 \mathrm{mmol}\right.$ ) and $\mathrm{Sml}_{3}(26 \mathrm{mg}$, $0.05 \mathrm{mmol})$.

Synthesis of LaS $_{2} .7 .2 \times 2.8 \mathbf{n m}^{2}$ nanoplates: In the glovebox, $\mathrm{Lal}_{3}(260 \mathrm{mg}, 0.50 \mathrm{mmol})$ and $\mathrm{S}^{(0)}$ (160 mg, $5.00 \mathrm{mmol}$ ) are mixed in vacuum-dried OLA $(10 \mathrm{~mL})$ at $45^{\circ} \mathrm{C}$ until they are fully dissolved (approx. $1 \mathrm{~h}$ ). A slightly scattering orange-red solution is obtained. Centrifugation in the glovebox at $8900 \mathrm{~g}$ during $3 \mathrm{~min}$ separates a white dispersion from the clear orange-red supernatant. The supernatant is transferred to a $125 \mathrm{~mL}$ three-neck flask connected to a Schlenk line. The reactant medium is heated to $220^{\circ} \mathrm{C}$ under $\mathrm{N}_{2}$ with a $25 \mathrm{~min}$ ramp, using a heating mantle. The reactant medium turns deep red around $180^{\circ} \mathrm{C}$. The temperature is maintained at $220^{\circ} \mathrm{C}$ during $1 \mathrm{~h}$. The reactant medium is cooled down to $120^{\circ} \mathrm{C}$ in $2-3$ min by removing the heating mantle and blowing cool air. Around $150^{\circ} \mathrm{C}$, the dispersion strongly precipitates into a creamy orange dispersion. At $70^{\circ} \mathrm{C}$, the flask is opened to air and toluene is added to the suspension until it fully redisperses $(30 \mathrm{~mL}) .15 \mathrm{~mL}$ of $\mathrm{MeCN}$ are added, the suspension is then centrifuged at $8900 \mathrm{~g}$ during $3 \mathrm{~min}$. The orange transparent supernatant is discarded, while the yellow pellet is redispersed in toluene $(15 \mathrm{~mL})$ and precipitated again using $\mathrm{MeCN}(5 \mathrm{~mL})$. After centrifugation at $8900 \mathrm{~g}$ during $3 \mathrm{~min}$, the clear transparent supernatant is discarded while the pellet is redispersed in toluene, leading to a red dispersion. Size-selective precipitation is performed using $\mathrm{MeCN}$ and a centrifugation step before NCs are dispersed in toluene. $\mathbf{1 1 . 6 \times 4 . 4} \mathbf{~ n m}^{\mathbf{2}}$ nanoplates: the protocol is similar to described above, except (i) quantity of $\mathrm{Lal}_{3}(520 \mathrm{mg}, 1.00 \mathrm{mmol})$, and (ii) the heating is performed by dipping the three-neck flask in a bath of molten $\mathrm{LiNO}_{3} / \mathrm{KNO}_{3}$ at the eutectic composition, at $\mathrm{T}=255^{\circ} \mathrm{C}$. The temperature in the reactant medium reaches $255^{\circ} \mathrm{C}$ and the temperature stabilizes within approx. $3 \mathrm{~min}$. Nanoellipsoids: the protocol is similar to described above, except (i) quantity of $\mathrm{S}^{(0)}(15 \mathrm{mg}$, $0.5 \mathrm{mmol}$ ). Dispersions are yellow instead of red in the case of nanoellipsoids.

First-Principle Calculations. Density Functional Theory (DFT) geometry optimizations were carried out with the CASTEP8.0 code $^{1}$ using a set of ultrasoft pseudopotentials ${ }^{2,3}$ with the PBEsol exchangecorrelation functional. ${ }^{4}$ Cell parameters and atomic positions were both relaxed. During the geometry optimizations, a convergence threshold of $0.02 \mathrm{eV} \AA^{-1}$ was used for the residual forces and $0.1 \mathrm{kbar}$ for the pressure. The cut-off energy for plane-waves was set to $700 \mathrm{eV}$. For the electronic band structures we used the full-potential linearized augmented plane wave (FLAPW) approach, as implemented in the WIEN2K code. ${ }^{5}$ A plane-wave cutoff corresponding to $\mathrm{R}_{M T} \mathrm{~K}_{\max }=7$ was used in all calculations. The radial wave functions inside the non-overlapping muffin-tin spheres were expanded up to $I_{\max }=12$. The charge density was Fourier expanded up to $G_{\max }=16 \AA^{-1}$. Total energy convergence was achieved with respect to the Brillouin zone (BZ) integration mesh with 500k-points. Because GGA exchange-correlation functionals are known to underestimate experimental band gaps, we used the modified Becke-Johnson (mBJ) functional which leads to excellent agreement with the experimental values for the energy separation between the highest occupied molecular orbital (HOMO) and the lowest unoccupied molecular orbital (LUMO). ${ }^{6}$ We used 10000 k-points in the BZ to compute the band derivatives and the density of states.

\section{Structural Characterization}


Powder X-ray diffraction (XRD) diagrams are acquired on a Rigaku Smartlab diffractometer with Cu K $\alpha$ radiation ( $\lambda=1.5416 \AA, 30 \mathrm{~mA}$ and $40 \mathrm{kV}$ ) with parallel beam setting in the $\theta-2 \theta$ geometry. $2 \theta$ range is screened between 10 and $80^{\circ}$ with data points collected every $0.05^{\circ}(2 \theta)$ using a scan speed of $35 \mathrm{~s}$ per step. Peak identification is performed using the cif files from the ICSD database, collection codes 53439 (EuS), $201012\left(\gamma-\mathrm{La}_{2} \mathrm{~S}_{3}\right), 641821\left(\mathrm{LaS}_{2}\right)$ and 24613 (LaOI). Apparent crystal size $\varepsilon_{h k l}$ is calculated using the Scherrer formula in most cases:

$$
B=B_{c r i s}=\frac{\lambda}{\varepsilon_{h k l} \cos \theta}
$$

$B$ is the integral width of the peak, $\lambda$ is the $X$-ray source wavelength and $\vartheta$ is the incident beam angle. $B$ is calculated for each separate experimental peak (hkl) by fitting it with a pseudo-Voigt function, using the WinPLOTR function (FullProfSuite). ${ }^{7} \varepsilon$ is then averaged from all values calculated on a single diagram. Le Bail refinement is performed on $\mathrm{LaS}_{2}$, using JANA2006 software. ${ }^{8}$ The size of crystalline domains is evaluated with a fundamental approach, taking geometrical parameters of the experimental setup into account.

Transmission electron microscopy (TEM). The TEM images of NCs are collected on a JEOL JEM-1400 microscope operating at $120 \mathrm{keV}$ and the HRTEM images on a field-emission FEI Talos F200X at $200 \mathrm{kV}$. Samples are prepared by depositing a drop of diluted NCs in toluene, TCE or hexane on a carbon-coated copper grid. Selected area electron diffraction (SAED) is performed with a camera distance of $20 \mathrm{~cm}$. Interreticular planes are deduced from distances calibrated with a known sample of silicium particles. Size distribution data are extracted from at least 100 particles on pictures taken on at least 3 distinct regions of a TEM grid.

Inductively coupled plasma-optical emission spectrometry (ICP-OES). The elemental composition of NCs and discards of the reaction is determined by ICP-OES performed on a Spectro Genesis spectrometer with a concentric nebulizer. Calibrated solution of $\mathrm{La}, \mathrm{Er}, \mathrm{Sm}, \mathrm{Eu}, \mathrm{I}$ and $\mathrm{S}$ are purchased from Inorganic Ventures. Solid samples are dissolved in $\mathrm{HNO}_{3}\left(70 \%\right.$ mas.) at $60{ }^{\circ} \mathrm{C}$ or $\mathrm{H}_{2} \mathrm{O}_{2}(30 \%)$ and then $\mathrm{HNO}_{3}(70 \%$ mas. $)$ at RT.

Scanning electron microscopy-energy dispersive spectroscopy (SEM-EDS) is performed on a JEOL $7500 \mathrm{~F}$ HRSEM equipped with an EDS detector. Acceleration tension of the source is $10 \mathrm{kV}$. La/S ratio is calculated from the average of EDS spectra measured on three distinct $100 \times 50 \mu \mathrm{m}^{2}$ areas of aggregated particles. Data are analyzed using the INCA software (Oxford). The sample is deposited on a Si wafer by dropcasting before a carbon sputtering step.

\section{Optical characterizations}

Absorption spectra of the dispersions are measured in $10 \mathrm{~mm}$ quartz cuvette, on a Cary 5000 UV-vis-NIR spectrophotometer (Agilent Technologies) from 800 to $200 \mathrm{~nm}$ with a $1 \mathrm{~nm}$ step. The spectra are reported relatively to a reference consisting of the cuvette filled with the solvent.

Luminescence experiments are performed on a FLS1000 fluorimeter (Edinburgh Instruments) equipped with a Xe lamp. Emission and excitation spectra are obtained from 20 successive scans with $2 \mathrm{~nm}$ slit bandwidths on both incident and emission sides, with $1 \mathrm{~nm}$ steps and $0.5 \mathrm{~s}$ per step. 
a

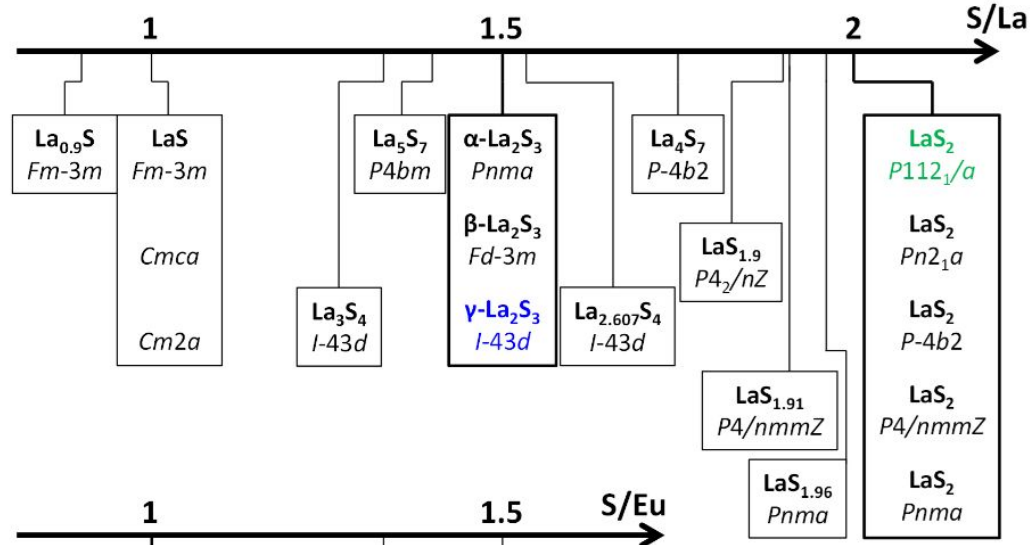

Figure S1. Phase diagrams of bulk a) lanthanum and b) europium sulfides as a function on S/La molar ratio. Structures from ICSD database.
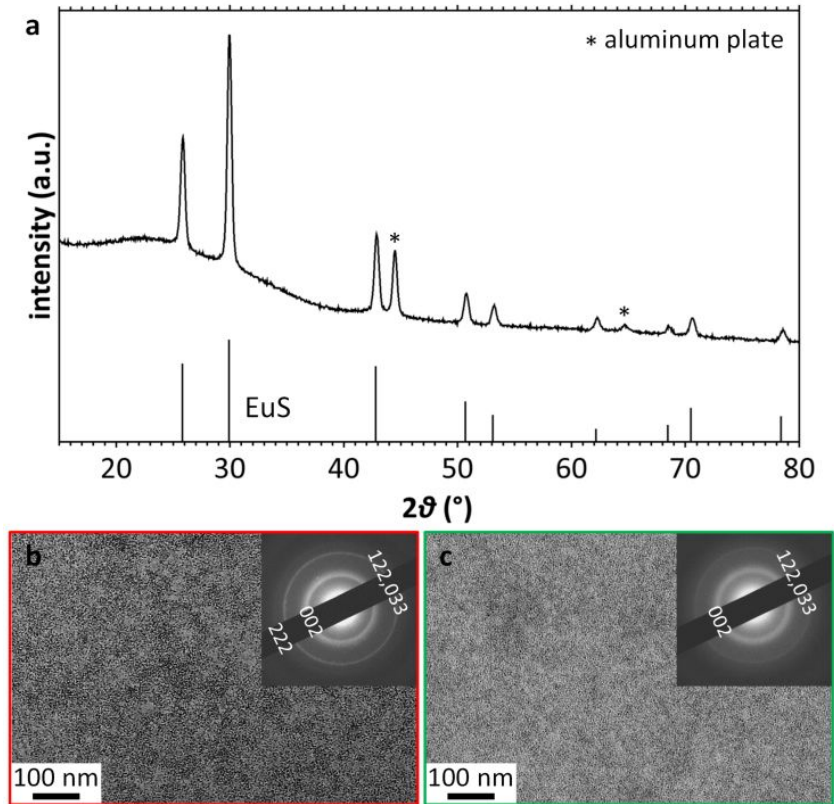

Figure S2. Structural characterization of europium sulfide NCs. a) XRD of NCs from $S^{(0)}$ at $220^{\circ} \mathrm{C}$ during $1 \mathrm{~h}$, TEM and SAED (inset) pictures of NCs b) from (TMS) $)_{2} \mathrm{~S}$ excess at $150^{\circ} \mathrm{C}$ during $10 \mathrm{~min}$, and c) $(\mathrm{TMS})_{2} \mathrm{~S}$ stoichiometric content at $150{ }^{\circ} \mathrm{C}$ during $10 \mathrm{~min}$. Diffraction rings in SAED pictures are indexed along with EuS structure. 


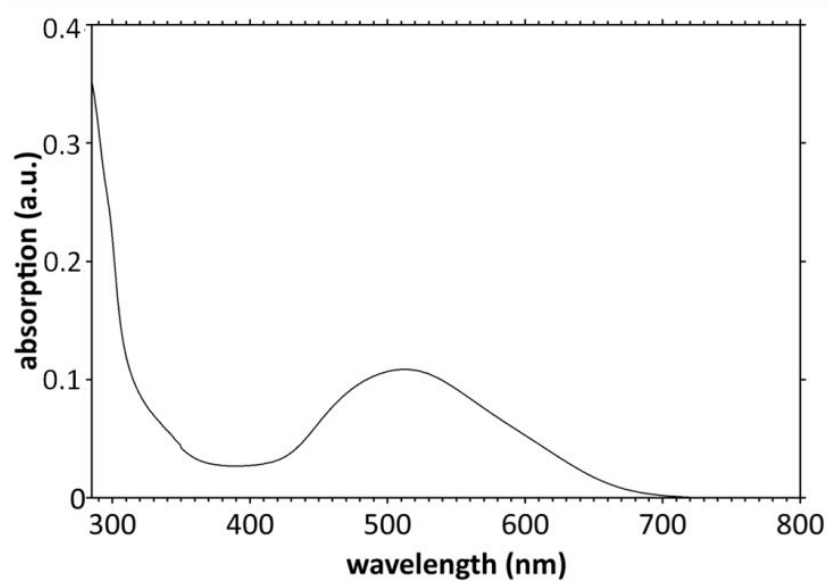

Figure S3. Absorption spectrum of EuS NCs from $\mathrm{S}^{(0)}$ at $220^{\circ} \mathrm{C}$ during $1 \mathrm{~h}$, dispersed in TCE.

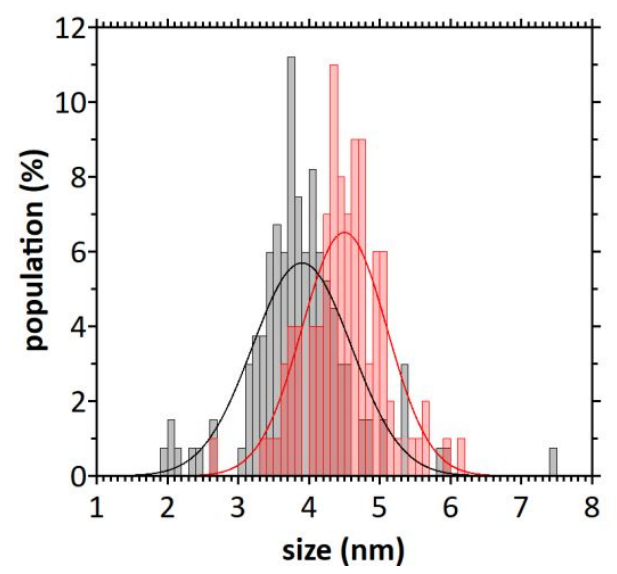

Figure S4. Size distribution of (black) $\mathrm{La}_{2} \mathrm{~S}_{3}$ and (red) $\mathrm{La}_{2} \mathrm{~S}_{3}: \mathrm{Er}^{3+}(10 \%) \mathrm{NCs}$. Calculated gaussian curves of (black) $3.9 \pm 0.7$ and (red) $4.5 \pm 0.6 \mathrm{~nm}$ populations. 
a
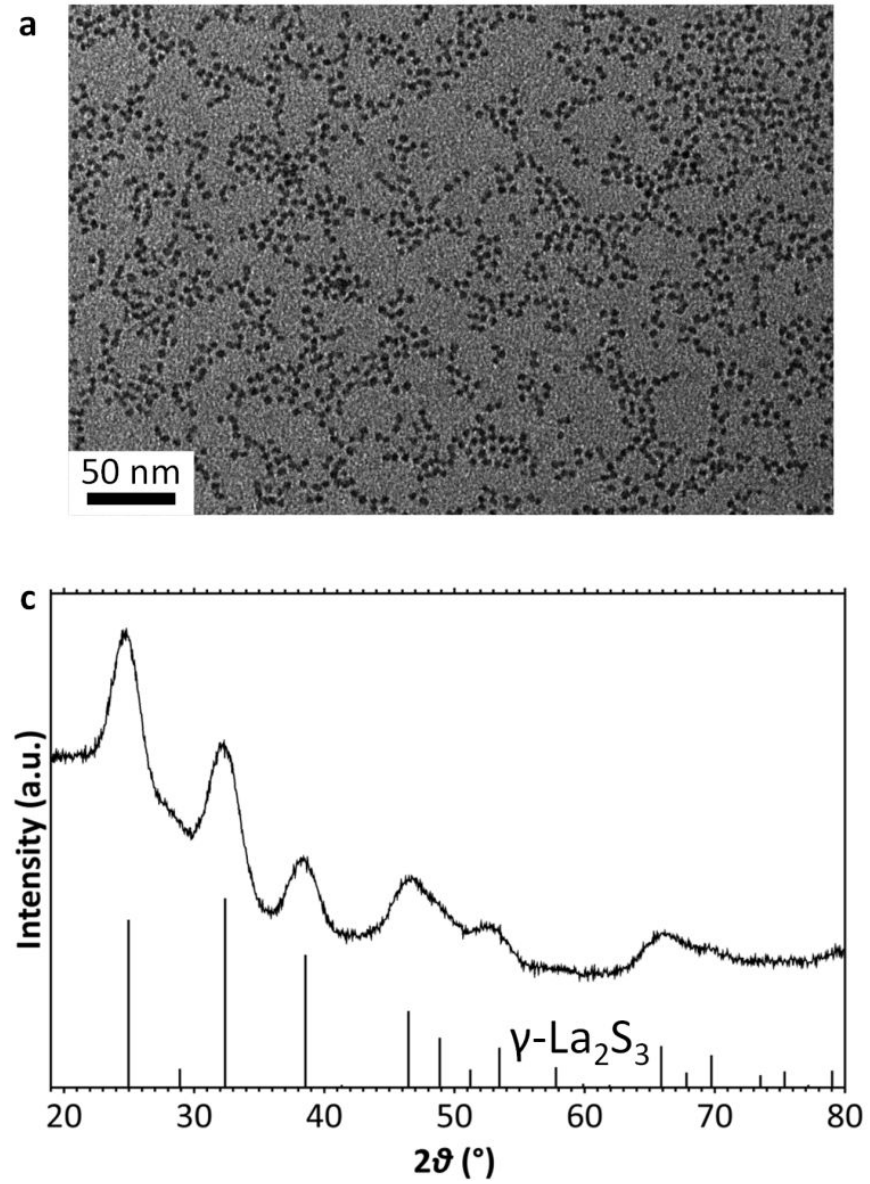

b
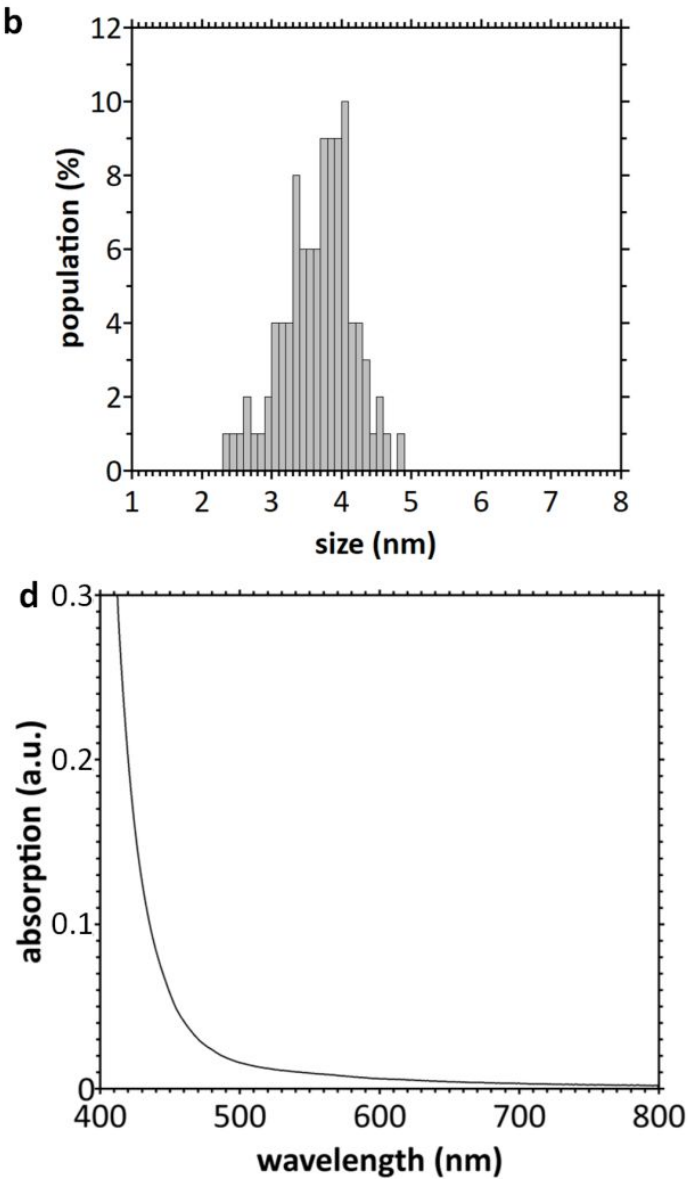

Figure S5. Structural and optical characterization of $\mathrm{La}_{2} \mathrm{~S}_{3}: \mathrm{Sm}^{3+}(10 \%)$. a) TEM picture, b) size distribution diagram of the NCs from TEM, size is $3.7 \pm 0.5 \mathrm{~nm}$ ), c) XRD diagram indexed along with $\gamma^{-}$ $\mathrm{La}_{2} \mathrm{~S}_{3}$ structure (apparent crystal size from Scherrer formula: $3.4 \pm 0.2 \mathrm{~nm}$ ) and d) absorption spectrum attributed to $\mathrm{Y}-\mathrm{La}_{2} \mathrm{~S}_{3}$ optical bandgap. As opposed to $\mathrm{La}_{2} \mathrm{~S}_{3}: \mathrm{Er}^{3+}$ (Figure 3), $\mathrm{Sm}^{3+}$ absorption features are not observed. It can be due to energy mismatch of atom-like $\mathrm{Sm}^{3+}$ levels relative to $\mathrm{\gamma}-\mathrm{La}_{2} \mathrm{~S}_{3}$ bandgap. According to ICP-OES, La:Sm ratio in the NCs is 8.93:1.07, which is similar to the initial 9:1 ratio. 


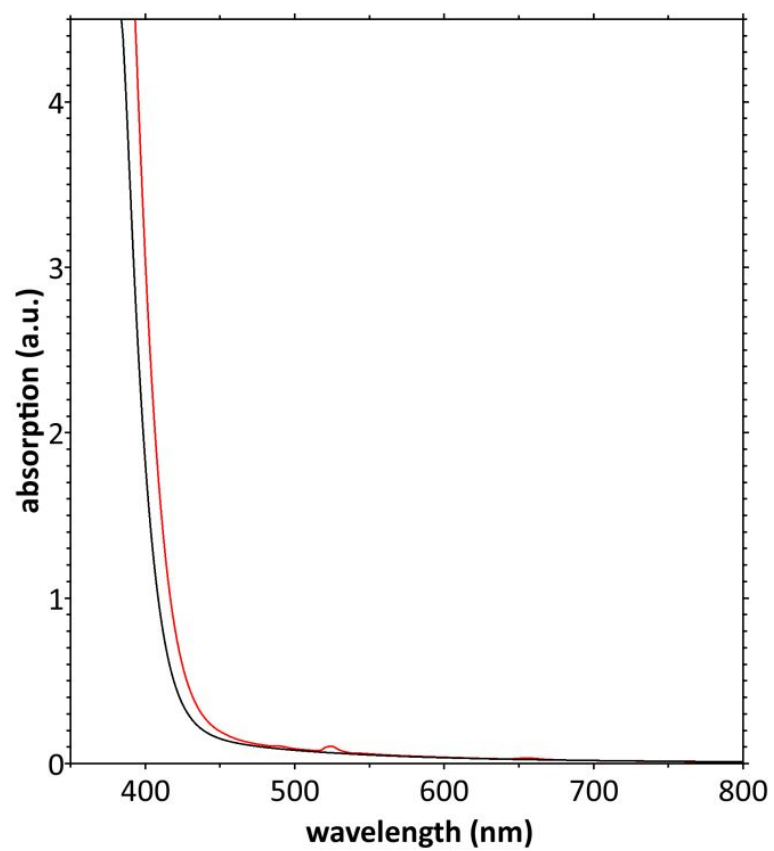

Figure S6. Absorption spectra of (black) $\mathrm{La}_{2} \mathrm{~S}_{3}$ and (red) $\mathrm{La}_{2} \mathrm{~S}_{3}: \mathrm{Er}^{3+}(10 \%) \mathrm{NCs}$. An optical density (O.D.) of approx. 0.1 is suited for luminescence measurements, in order to avoid multiple absorption events. At $\lambda=420 \mathrm{~nm}$, O.D. $=0.5$, and then O.D. dramatically increases for lower $\lambda$. Figure $3 \mathrm{e}$, the loss of excitation intensity can then be related to O.D reaching out-of-range values.

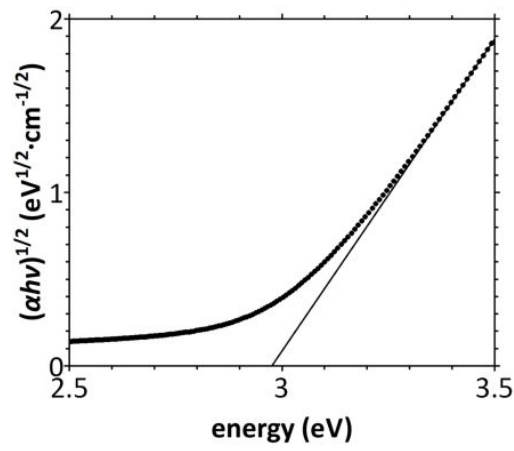

Figure S7. Tauc plot for dispersed $\mathrm{La}_{2} \mathrm{~S}_{3} \mathrm{NCS}$.

The Tauc model is based on the relationship (2) between the absorption coefficient $\alpha$, the photon energy $h v$ and the bandgap energy $E_{g}$ :

$$
\alpha h v=\mathrm{B}\left(h v-E_{g}\right)^{\mathrm{n}}
$$

where $\mathrm{B}$ is a constant and $\mathrm{n}=2$ for allowed transitions and an indirect bandgap. ${ }^{9-11} \mathrm{E}_{\mathrm{g}}$ can then be deduced by a linear fit of $v(\alpha h v)$ (indirect bandgap) or $(\alpha h v)^{2}$ (direct) as a function of $h v$ and extrapolation of the fit to $\alpha h v=0$. For relatively low absorption $\mathrm{A}(\mathrm{A}<1)$, the absorption coefficient of a perfectly non-scattering dispersion follows the linear Beer-Lambert law:

$$
\mathrm{A}=\alpha \mid
$$

with I the optical path length $(1 \mathrm{~cm})$. Tauc plots for $\mathrm{La}_{2} \mathrm{~S}_{3} \mathrm{NCs}$ are compared Figure S6, whether an indirect or direct bandgap is considered. An energy bandgaps of $2.98 \mathrm{eV}$ is deduced from the plot. Zhukov et al. confirmed the $S 3 p \rightarrow$ La $5 d$ nature of the transition via DFT calculations. ${ }^{12}$ However, the 
direct or indirect nature of the band gap remains unclear..$^{13}$ Considering a direct bandgap $(n=1 / 2)$ leads to an optical bandgap energy of $3.16 \mathrm{eV}$. Although the nature of the electronic structure of $\mathrm{Y}$ $\mathrm{La}_{2} \mathrm{~S}_{3}$ is not elucidated yet, the bandgap energy is significantly higher than the bulk structure, where Eg is reported at $2.9 \mathrm{eV}$ or less. ${ }^{13}$ Tauc plot previously enabled to extract the bandgap energy of $\gamma^{-}$ $\mathrm{La}_{2} \mathrm{~S}_{3} 10-30 \mathrm{~nm} \mathrm{NCs}$ from the reflectance spectrum of the powder, considering a direct bandgap. ${ }^{14}$ It was found to be $2.97 \mathrm{eV}$. This value lies between the energy reported for the bulk $\mathrm{\gamma}-\mathrm{La}_{2} \mathrm{~S}_{3}{ }^{13}$ and for $3.4 \pm 0.1 \mathrm{~nm}$ nanoparticles described here.
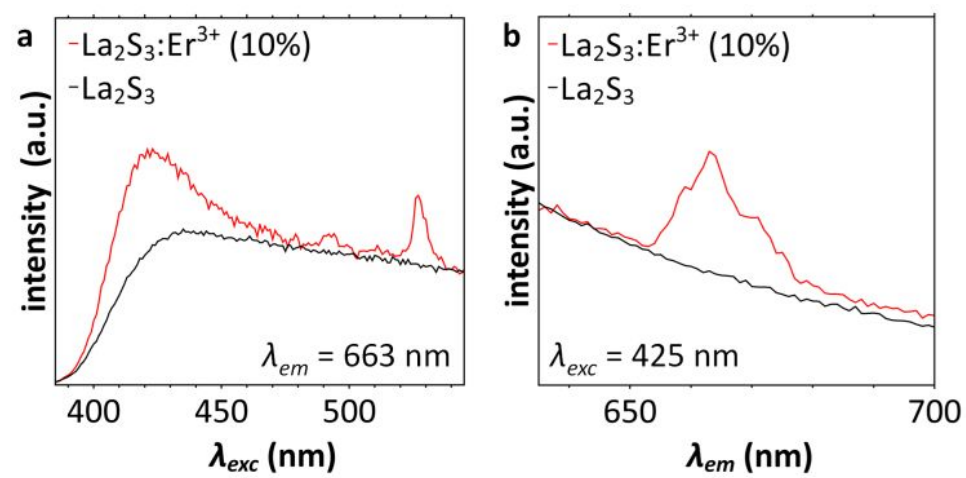

Figure 58. Luminescence of $\mathrm{La}_{2} \mathrm{~S}_{3}$ and $\mathrm{La}_{2} \mathrm{~S}_{3}: \mathrm{Er}^{3+}(10 \%) \mathrm{NCs}$. a) Excitation and b) emission spectra confirm that the narrow features are related to $\mathrm{Er}^{3+}$. In $\mathrm{La}_{2} \mathrm{~S}_{3}, \mathrm{OLA}$ is suggested to be responsible for the residual emission (non-zero background). ${ }^{15}$

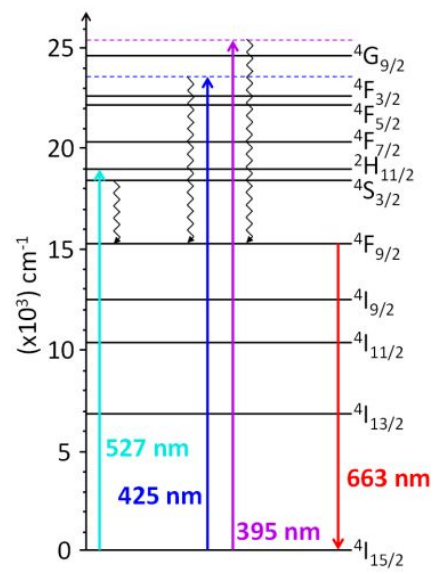

Figure S9. Energy diagram of $\mathrm{Er}^{3+} 4 \mathrm{f}$ levels with spin-orbit splitting. ${ }^{16}$ Excitation at $527 \mathrm{~nm}$ corresponds to ${ }^{4} \mathrm{I}_{15 / 2} \rightarrow^{2} \mathrm{H}_{11 / 2}$ transition, while excitations at 425 and $35 \mathrm{~nm}$ cannot be attributed to any absorption via $\mathrm{Er}^{3+} 4 \mathrm{f} \rightarrow 4 \mathrm{f}$ transition. In all cases, emission of $\mathrm{Er}^{3+}$ is observed at $663 \mathrm{~nm}$, corresponding to ${ }^{4} \mathrm{~F}_{9 / 2} \rightarrow{ }^{4} \mathrm{I}_{15 / 2}$ transition. Non-radiative de-excitation is proposed to occur, leading to ${ }^{4} \mathrm{~F}_{9 / 2}$ level being populated prior to emissive de-excitation. 


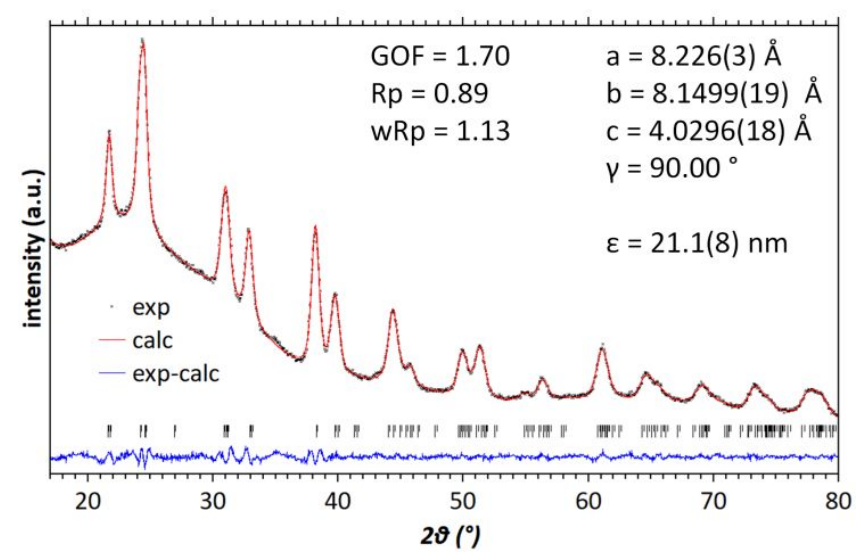

Figure S10. Le Bail refinement of $\mathrm{LaS}_{2}$ ellipsoidal NCs.

$\mathrm{LaS}_{2}$ crystallizes in the $\mathrm{P} 112_{1}$ space group (monoclinic cell) with $\gamma=90.00^{\circ}$ and $\mathrm{a} \approx \mathrm{b} \approx 2 \mathrm{c}$. This gives rise too many peaks overlapping between inequivalent interreticular planes. For instance, the first experimental peak at $2 \vartheta=21.7^{\circ}$ is the convolution of (200) and (020), whereas (210), (101) and (011) are at the origin of the peak at $2 \vartheta=24.4^{\circ}$. As a consequence, the Scherrer formula does not enable to calculate apparent crystal size. Indeed, this technique requires the deconvolution of each inequivalent peak, which is fitted as a pseudo-Voigt function. LeBail refinement is then preferred, with the apparent crystal size (pure Lorentzian function) being a single variable of the fit in the whole $2 \vartheta$ range. 

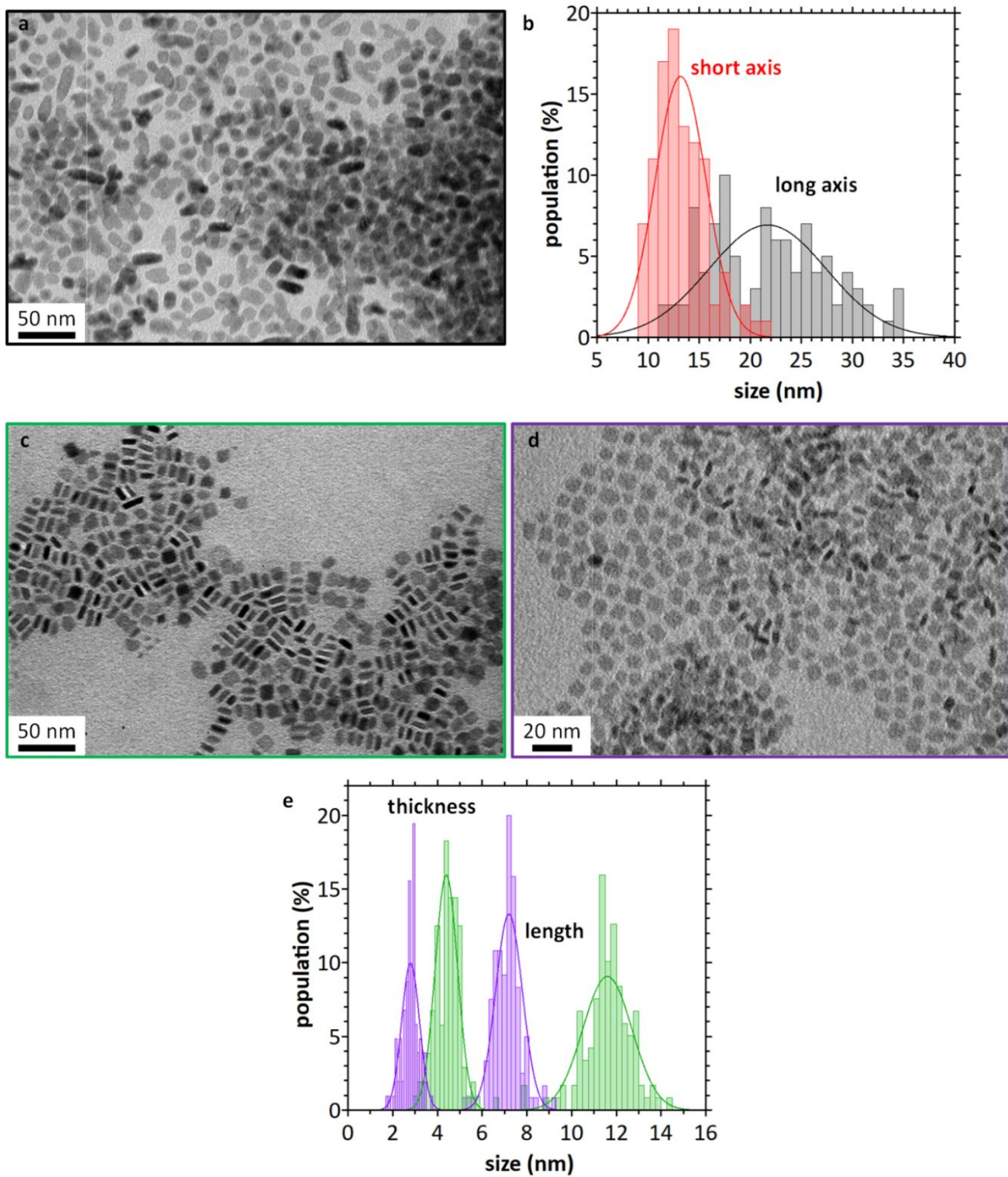

Figure S11. Size distribution of $\mathrm{LaS}_{2}$ NCs. a) TEM picture of aggregated ellipsoidal NCs. The grid is prepared from a drop of concentrated NCs in a TCE/MeCN mixture instead of TCE (Figure 4a). No thin edges are observed. This is attributed to the isotropic morphology of the ellispsoids, as opposed to nanoplates. b) Size distribution diagram of ellipsoids, separating the long axis and short axis for each particle. The aspect ratio, calculated as the ratio between average long and short axes, is 1.6. c) TEM picture of $11.6 \times 4.4 \mathrm{~nm}^{2}$ nanoplates. The grid is prepared from a drop of NCs in hexane instead of TCE (Figure $4 \mathrm{~b}$ ), yielding higher proportions of particle standing on an edge. d) TEM picture of $7.2 \times 2.8 \mathrm{~nm}^{2}$ nanoplates. The grid is prepared from a drop of NCs in TCE, such as Figure 4c. e) Size distribution diagram of both samples of nanoplates, considering thickness separately from lengths. Note that the base of the nanoplates is not systematically a perfect square. The average ratio between the longer and the shorter lateral length of a nanoplate is 1.1. 

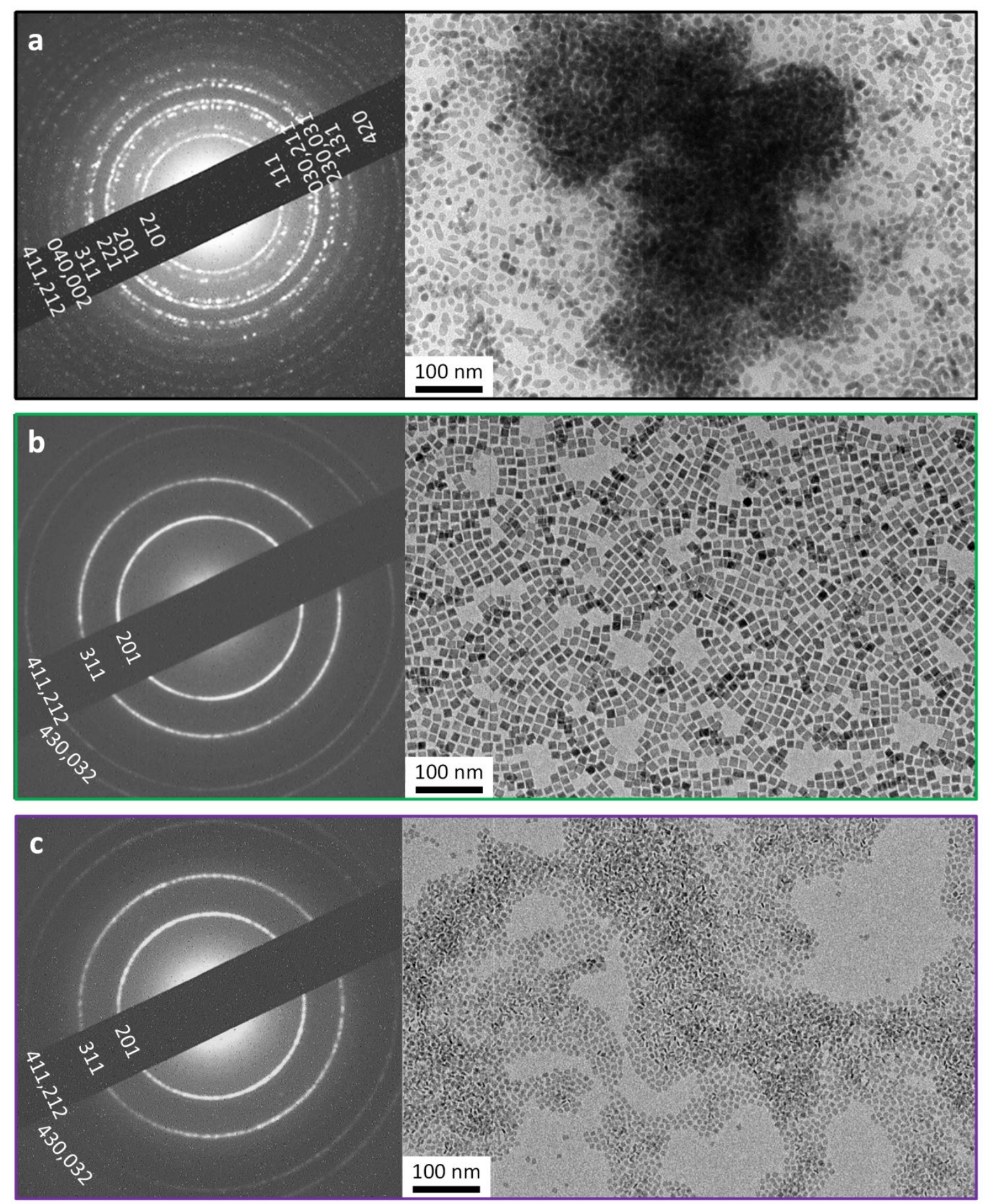

Figure S12. SAED and corresponding TEM pictures of $\mathrm{LaS}_{2} \mathrm{NCs}$. a) Ellipsoids, b) $11.6 \times 4.4 \mathrm{~nm}^{2}$ nanoplates, and c) $7.2 \times 2.8 \mathrm{~nm}^{2}$ nanoplates. 


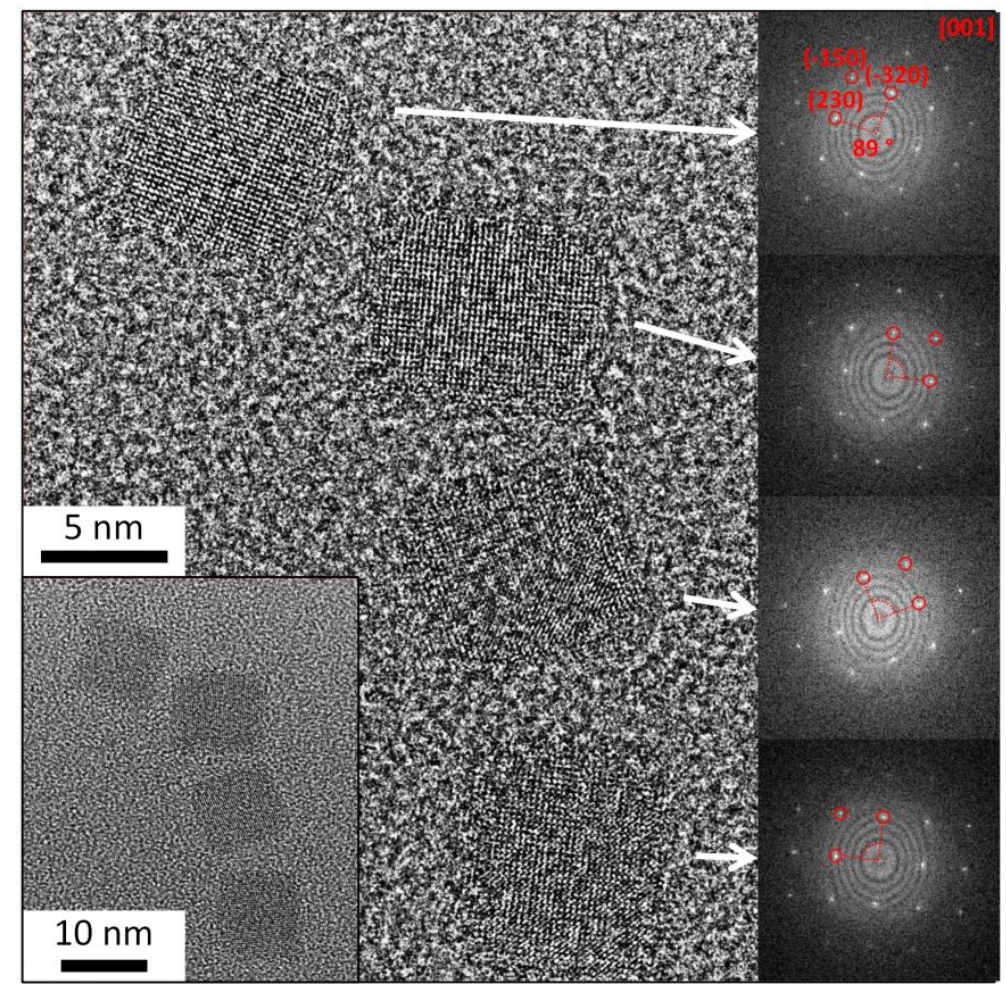

Figure S13. HRTEM pictures of $11.6 \times 4.4 \mathrm{~nm}^{2} \mathrm{LaS}_{2}$ nanoplates at two distinct magnifications and corresponding FFT (insets on the right). Indexation of interreticular planes along with $\mathrm{LaS}_{2}$ structure is the same on all nanoplates, with systematically (i) [001] as the zone axis, and (ii) [230] and [-320] as main directions for the growth of the square nanoplates. 

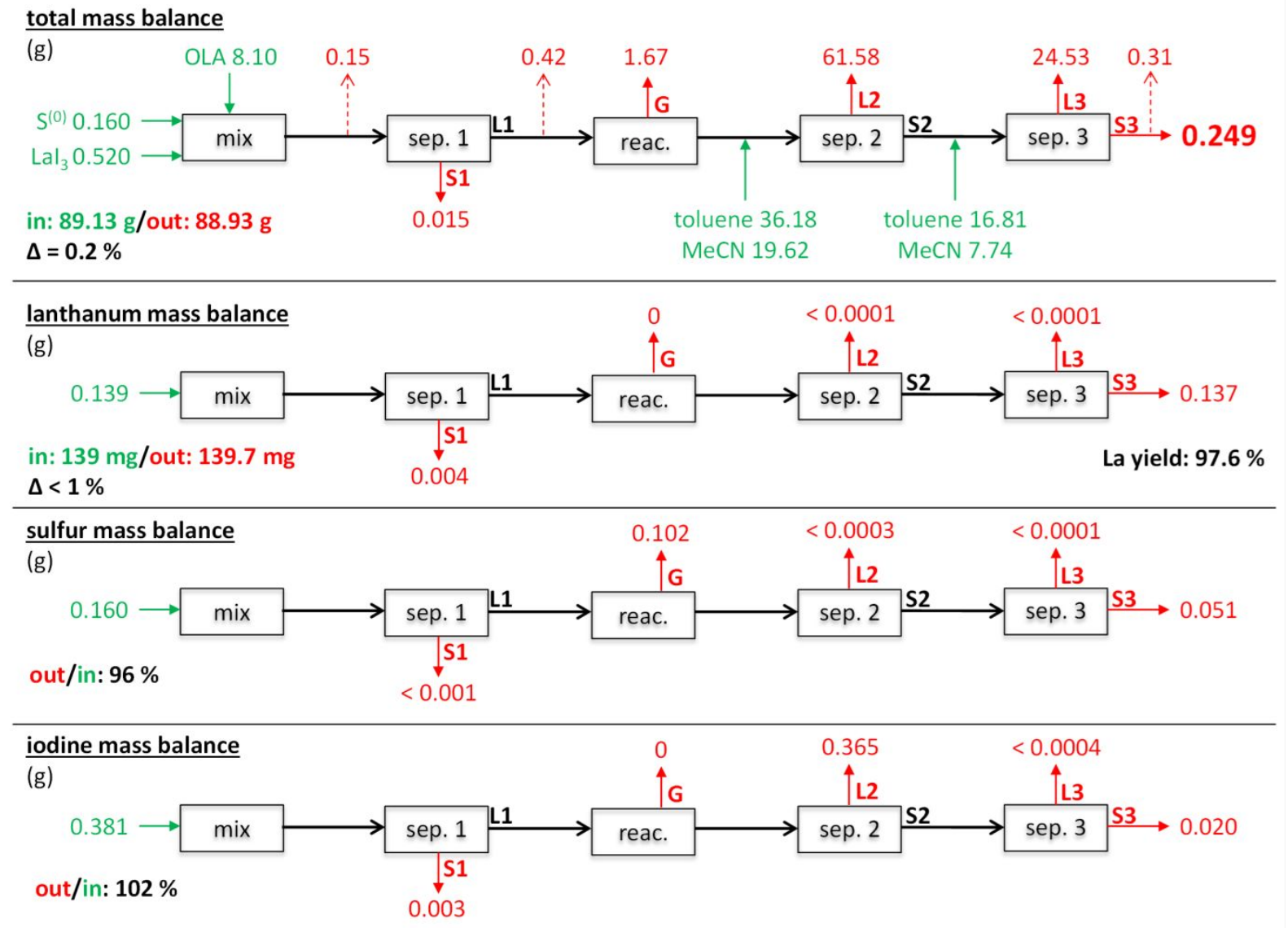

Figure S14. Total and elemental mass balances from the synthesis of $11.6 \times 4.4 \mathrm{~nm}^{2} \mathrm{LaS}_{2}$ nanoplates. Species added are in green, species extracted out in red. mix: mixing step, sep.: separation, reac.:reaction. G, S and L labels indicate the physical state of species, gaseous, solid and liquid, respectively. Total mass balance: dashed lines correspond to material lost during transfers. Elemental masses out are measured by ICP. Correction factors are applied to take loss of material during transfers into account.

out/in mass ratios above 1 for lanthanum and iodine are due to uncertainty on initial mass measurement of anhydrous $\mathrm{Lal}_{3}$ in the glovebox. The conversion of $\mathrm{Lal}_{3}$ into $\mathrm{LaOl}$ during the mixing step is very minor (2.4\%). It is attributed to partial oxidation of precursors prior to the synthesis. Then, only trace amounts of La are detected in supernatants of the purification steps ( $L 2$ and L3), demonstrating the quantitative conversion of La species into $\mathrm{LaS}_{2}$. Liquid aliquots are treated under vacuum at $60{ }^{\circ} \mathrm{C}$ to evaporate toluene and $\mathrm{MeCN}$, prior to addition of $\mathrm{HNO}_{3}$ ( $70 \%$ mas.) at RT. Gaseous species are recovered by bubbling exhaust $\mathrm{N}_{2}$ flow in $\mathrm{KOH} 50 \%$ mas. Initial excess of $\mathrm{S}^{(0)}$ source is recovered in $\mathrm{G}$, which is attributed to the formation of $\mathrm{H}_{2} \mathrm{~S}_{(\mathrm{g})}$ during the reaction. Most iodine is recovered in the supernatant of the first purification step. 


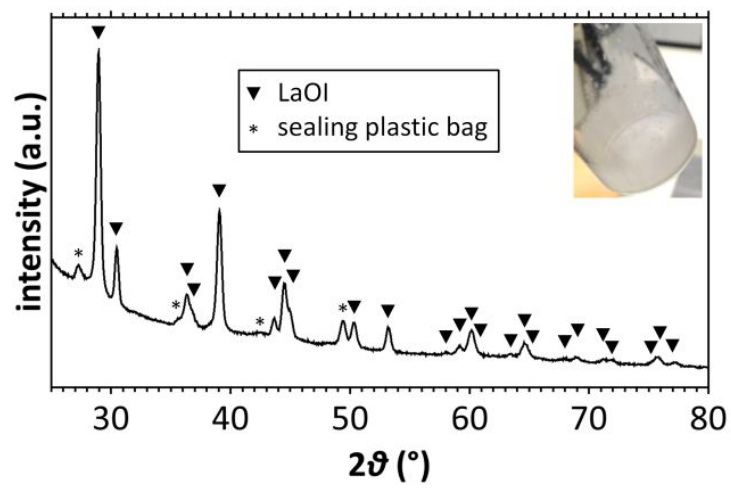

Figure S15. XRD diagram of the precipitate recovered from the dissolution of $\mathrm{Lal}_{3}$ in OLA. LaOI is obtained as a pure phase. The dissolution is performed in a $\mathrm{N}_{2}$-filled glovebox, as well as the washing of the precipitate (addition of toluene, centrifugation and recovery of pellet). The sample is sealed with a plastic bag in the glovebox prior to XRD experiment. The additional peaks are due to the plastic.

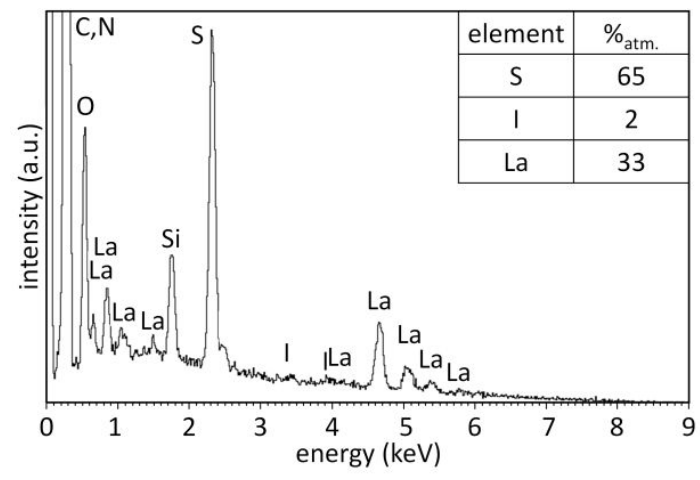

Figure S16. SEM-EDS spectrum of a region of aggregated $\mathrm{LaS}_{2} \mathrm{NCs}$. The quantitive elemental analysis (inset up-right) is the average of three regions. Si detection is attributed to a contamination from sample preparation or SEM chamber. It is not considered for quantification, such as $\mathrm{O}, \mathrm{C}$ and $\mathrm{N}$.
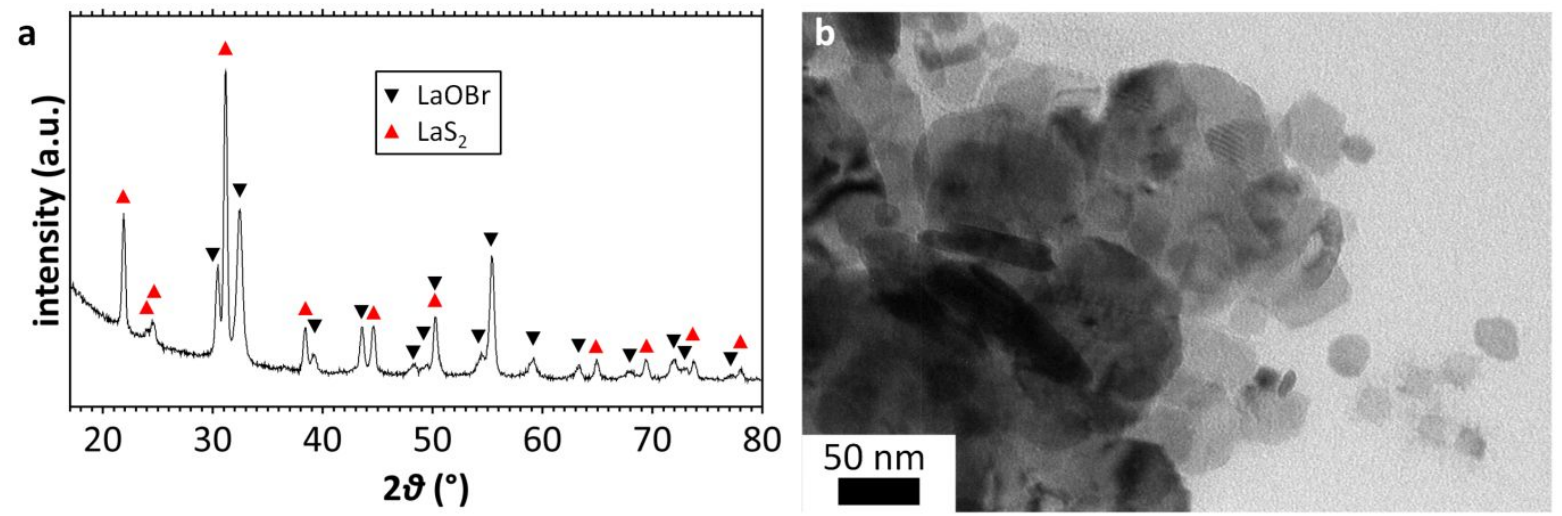

Figure S17. $\mathrm{LaOBr}-\mathrm{LaS}_{2}$ mixture from $\mathrm{LaBr}_{3}$ and $\mathrm{S}^{(0)}$ in OLA at $330{ }^{\circ} \mathrm{C}$ during $1 \mathrm{~h}$. a) XRD diagram and b) TEM picture of the resulting material. $\mathrm{LaOBr}$ is indexed along according to ICSD card number 84336 . No $\mathrm{LaS}_{2}$ is detected by XRD upon a similar experiment at $220^{\circ} \mathrm{C}$ during $1 \mathrm{~h}$. 


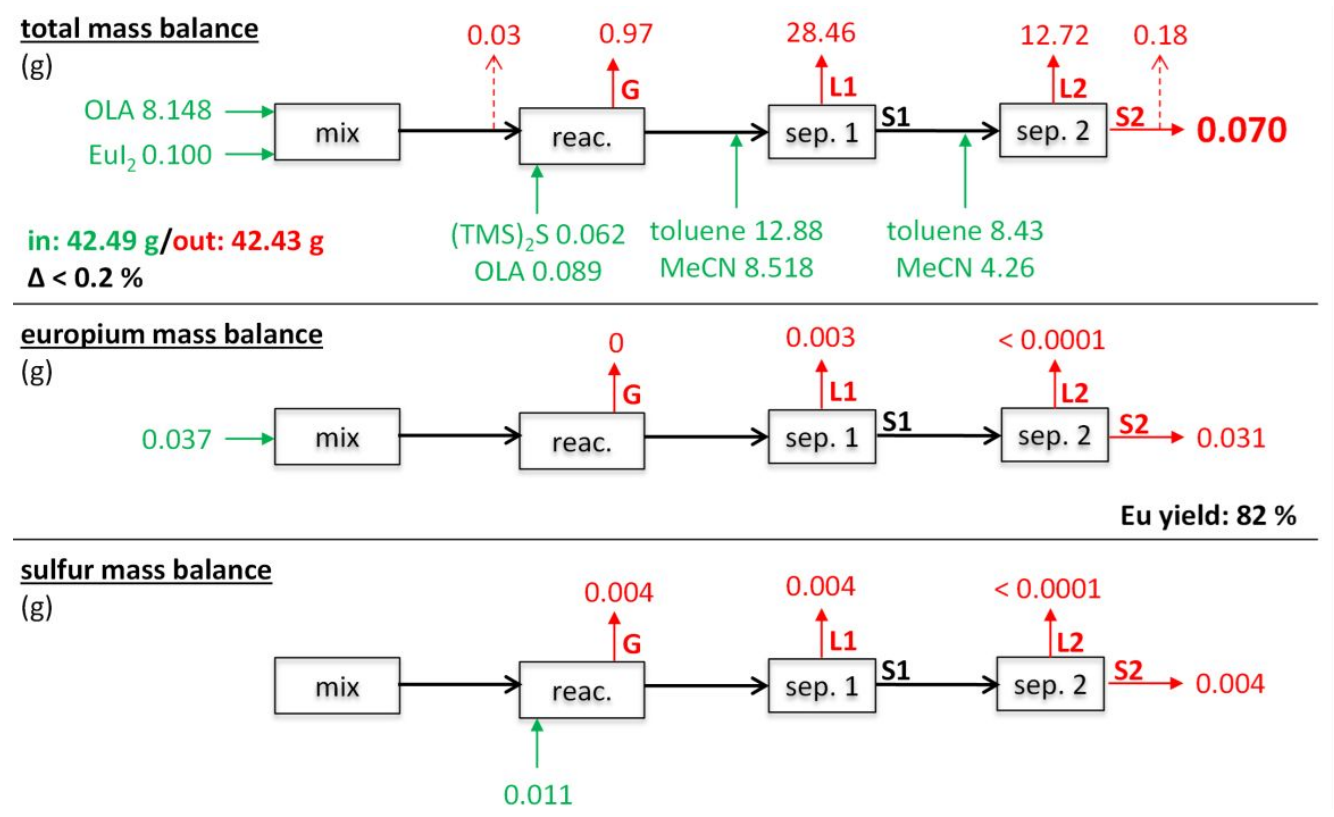

Figure S18. Total and elemental mass balances from the synthesis of $5.9 \mathrm{~nm}$ EuS NCs. Species added are in green, species extracted out in red. mix: mixing step, sep.: separation, reac.:reaction. $\mathrm{G}, \mathrm{S}$ and $\mathrm{L}$ labels indicate the physical state of species, gaseous, solid and liquid, respectively. Total mass balance: dashed lines correspond to material lost during transfers. Elemental masses out are measured by ICP-OES. Correction factors are applied to take the loss of material during transfers into account. Recovery of Eu in L1 indicates that the reaction is not quantitative. This is due to short reaction time (10 $\mathrm{min})$. out/in mass ratio above 1 for sulfur is attributed to uncertainty on initial volume measurement of (TMS $)_{2} \mathrm{~S}$ in the glovebox. Gaseous species are recovered by bubbling exhaust $\mathrm{N}_{2}$ flow in $\mathrm{KOH} 50 \%$ mas. Initial excess of (TMS) $)_{2} \mathrm{~S}$ source is partially recovered in $\mathrm{G}$, which is attributed to the formation of $\mathrm{H}_{2} \mathrm{~S}_{(\mathrm{g})}$ during the reaction. Sulfur is also partially recovered in $\mathrm{L} 1$, which again indicates that the reaction has stopped before species fully reacted in the medium. 

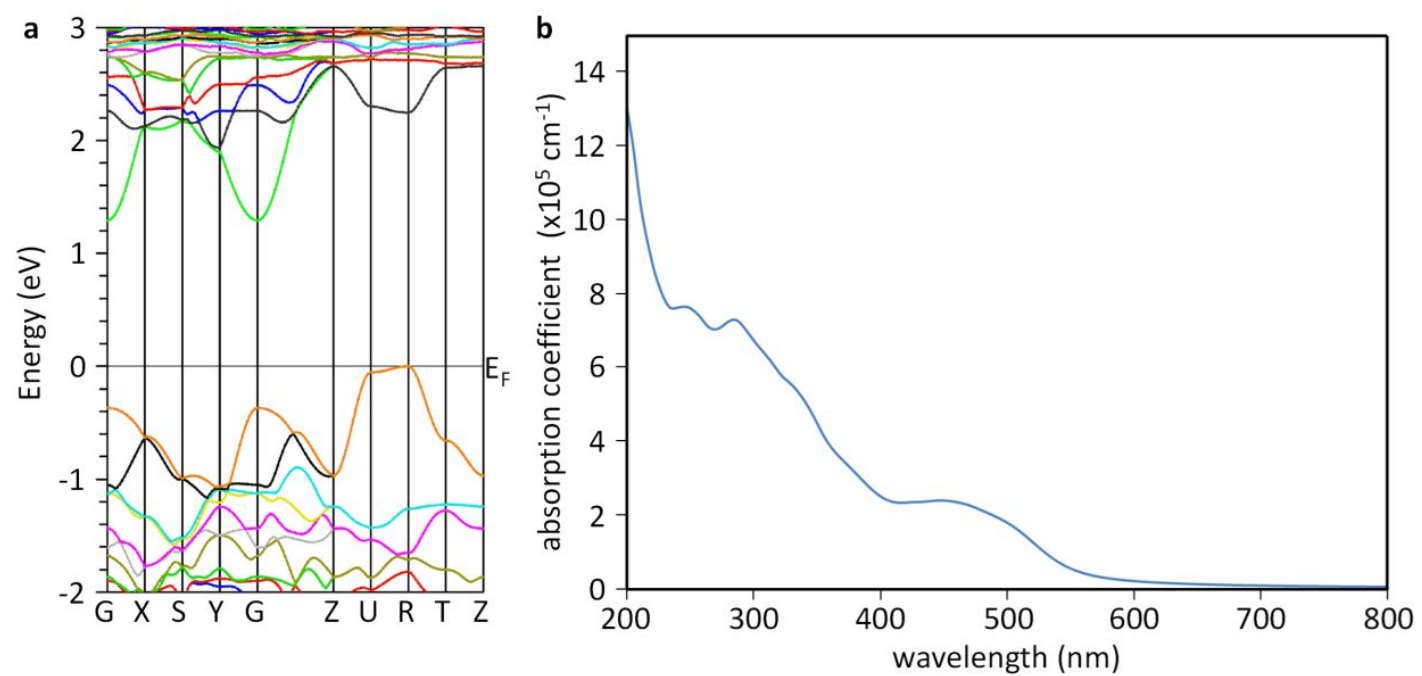

Figure S19. a) Electronic band structure of $\mathrm{LaS}_{2}$, space group P112 1 /a (14), calculated from ICSD card 641821, and b) calculated absorption coefficient of $\mathrm{LaS}_{2}$. The band structure calculations performed for pristine $\mathrm{LaS}_{2}$ confirm the indirect band-gap of the compound with valence band maximum (VBM) located at $\mathrm{R}$ point and conduction band minimum (CBM) located at the $\Gamma$ point of the Brillouin zone. The computed band gap of $\mathrm{LaS}_{2}$ compound is determined to be $1.35 \mathrm{eV}$, which is responsible for very low absorption around 600-500 nm (Figure S19 b). The absorption coefficient becomes important from $520 \mathrm{~nm}$ due to direct band gap located at R point $(2.25 \mathrm{eV})$. Accordingly, the material is expected to be yellow.
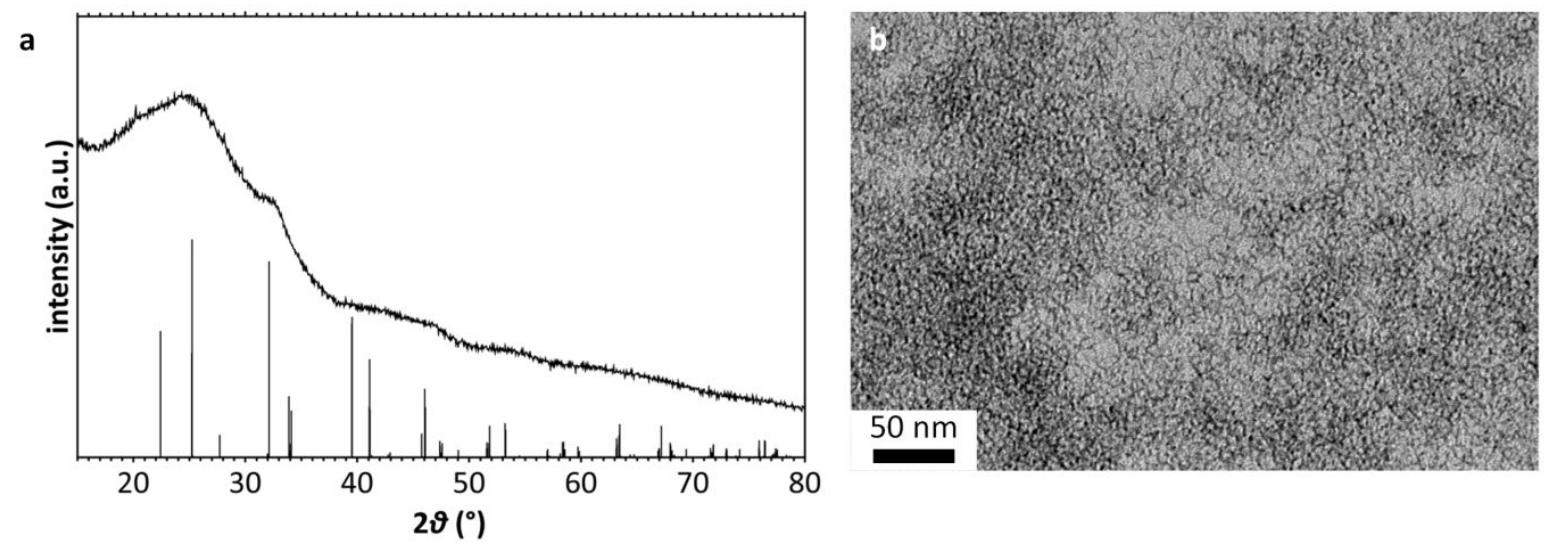

Figure S20. Structural characterization of $\mathrm{GdS}_{2} \mathrm{NCs}$ from $\mathrm{Gdl}_{3}$. a) XRD diagram and b) TEM picture of gadolinium sulfide $\mathrm{NCs}$ from $\mathrm{Gdl}_{3}$ and $\mathrm{S}^{(0)}$ reacted in OLA at $220^{\circ} \mathrm{C}$ for $1 \mathrm{~h}$. Experimental XRD pattern is compared to $\mathrm{GdS}_{2}\left(\mathrm{P} 12_{1} / \mathrm{a} 1\right)$ structure (ICSD card number 421335). 

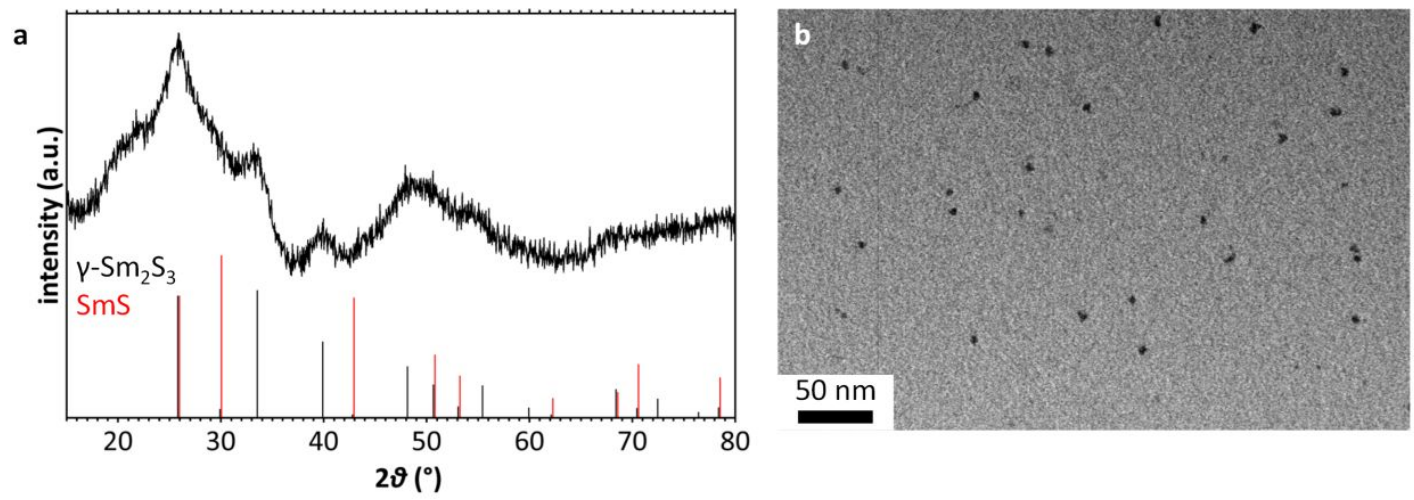

Figure S21. Structural characterization of $\mathrm{Sm}_{2} \mathrm{~S}_{3} \mathrm{NCs}$ from $\mathrm{Sml}_{2}$. a) XRD diagram and b) TEM picture of samarium sulfide $\mathrm{NCS}$ from $\mathrm{Sml}_{2}$ and $(\mathrm{TMS})_{2} \mathrm{~S}$ reacted in OLA at $150{ }^{\circ} \mathrm{C}$ for $10 \mathrm{~min}$. Comparing experimental XRD pattern to $\mathrm{SmS}(\mathrm{Fm}-3 \mathrm{~m})$ and $\mathrm{Sm}_{2} \mathrm{~S}_{3}$ (I-43d) structures (ICSD card numbers 52100 and 72822 , respectively) enables to identify the formation of the sesquisulfide rather than the monosulfide.
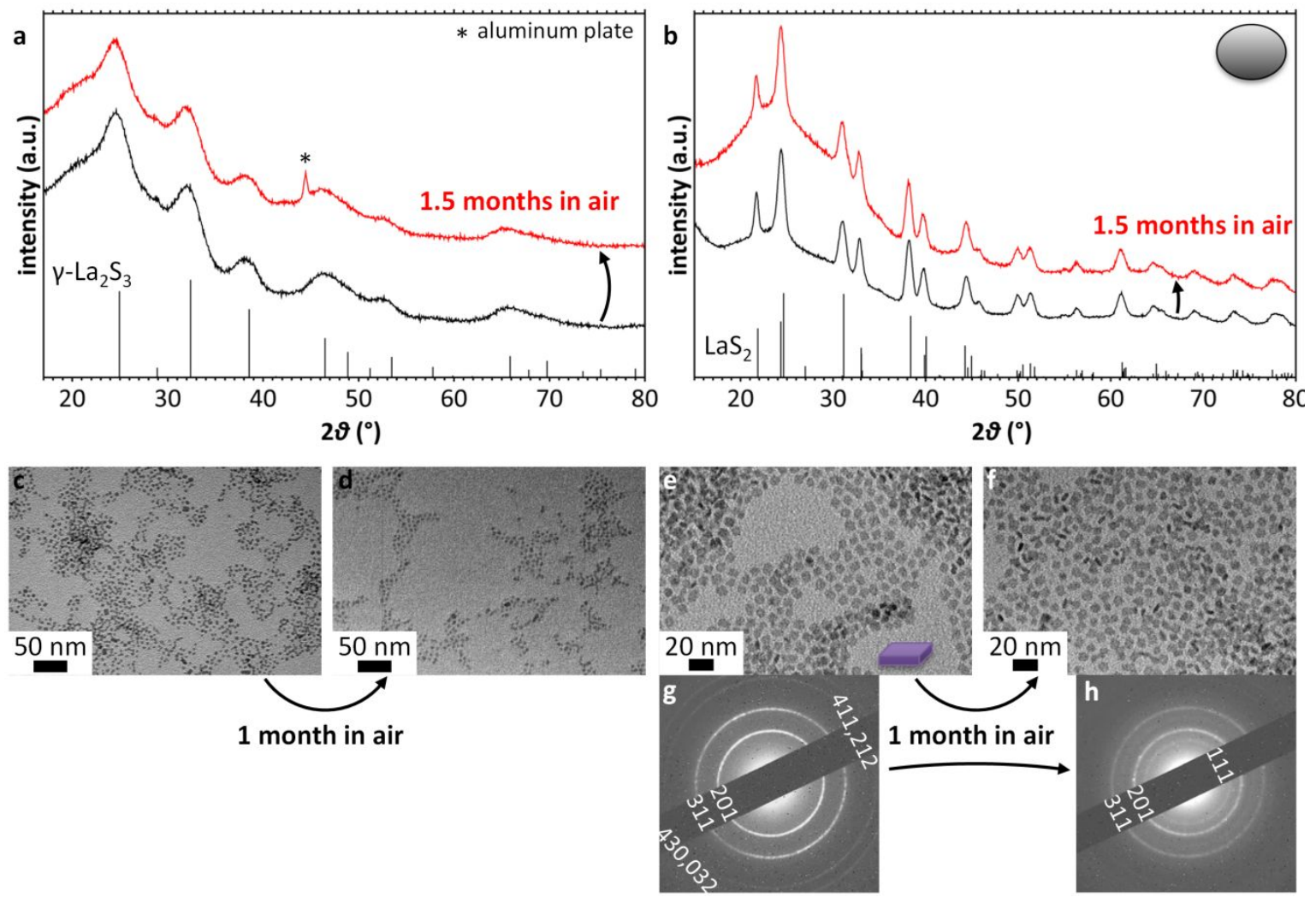

Figure S22. Stability of lanthanum sulfide NCs upon exposure to air. a,b) XRD patterns of $\mathrm{La}_{2} \mathrm{~S}_{3} \mathrm{NCS}$ and LaS $_{2}$ ellipsoidal NCs, respectively, (black) less than 2 days after sample preparation (dropcasting a concentrated dispersion of NCs on a glass slide) and (red) same dried samples left in air at RT for 1.5 months. c-f) TEM pictures of c, d) $\mathrm{La}_{2} \mathrm{~S}_{3} \mathrm{NCs}$ and e, f) $7.2 \times 2.8 \mathrm{~nm}^{2} \mathrm{LaS}_{2}$ nanoplates with $\mathrm{g}, \mathrm{h}$ ) corresponding SAED pictures indexed along with $\mathrm{LaS}_{2}$ structure. c), e) and g) pictures are from TEM grids prepared less than $2 \mathrm{~h}$ before observation, d), f) and $\mathrm{h}$ ) are the exact same grids left 1 month on air at RT. 


\section{References}

(1) Clark, S. J.; Segall, M. D.; Pickard, C. J.; Hasnip, P. J.; Probert, M. I. J.; Refson, K.; Payne, M. C. First Principles Methods Using CASTEP. Zeitschrift für Krist. - Cryst. Mater. 2005, 220, 567-570.

(2) Vanderbilt, D. Soft Self-Consistent Pseudopotentials in a Generalized Eigenvalue Formalism. Phys. Rev. B 1990, 41, 7892-7895.

(3) Garrity, K. F.; Bennett, J. W.; Rabe, K. M.; Vanderbilt, D. Pseudopotentials for High-Throughput DFT Calculations. Comput. Mater. Sci. 2014, 81, 446-452.

(4) Perdew, J. P.; Ruzsinszky, A.; Csonka, G. I.; Vydrov, O. A.; Scuseria, G. E.; Constantin, L. A.; Zhou, X.; Burke, K. Restoring the Density-Gradient Expansion for Exchange in Solids and Surfaces. Phys. Rev. Lett. 2008, 100, 136406.

(5) Blaha, P.; Schwarz, K.; Madsen, G. K. H.; Kvasnicka, D.; Luitz, J. WIEN2k, An Augmented Plane Wave Plus Local Orbitals Program for Calculating Crystal Properties; Schwarz, K., E., Ed.; Techn. Universitat, 2001.

(6) Tran, F.; Blaha, P. Accurate Band Gaps of Semiconductors and Insulators with a Semilocal Exchange-Correlation Potential. Phys. Rev. Lett. 2009, 102, 226401.

(7) Roisnel, T.; Rodríquez-Carvajal, J. WinPLOTR: A Windows Tool for Powder Diffraction Pattern Analysis. Mater. Sci. Forum 2001, 378-381, 118-123.

(8) Petrícek, V.; Dušek, M.; Palatinus, L. Crystallographic Computing System JANA2006: General Features. Zeitschrift fur Krist. 2014, 229, 345-352.

(9) Tauc, J.; Grigorovici, R.; Vancu, A. Optical Properties and Electronic Structure of Amorphous Germanium. Phys. status solidi 1966, 15, 627-637.

(10) Sangiorgi, N.; Aversa, L.; Tatti, R.; Verucchi, R.; Sanson, A. Spectrophotometric Method for Optical Band Gap and Electronic Transitions Determination of Semiconductor Materials. Opt. Mater. 2017, 64, 18-25.

(11) Raciti, R.; Bahariqushchi, R.; Summonte, C.; Aydinli, A.; Terrasi, A.; Mirabella, S. Optical Bandgap of Semiconductor Nanostructures: Methods for Experimental Data Analysis. J. Appl. Phys. 2017, 121, 234304.

(12) Zhukov, V.; Mauricot, R.; Gressier, P.; Evain, M. Band Electronic Structure Study of Some Doped and Undoped Y$\mathrm{Ln}_{2} \mathrm{~S}_{3}(\mathrm{Ln}=\mathrm{La}, \mathrm{Ce}, \mathrm{Pr}$, and Nd) Rare Earth Sulfides through LMTO-TB Calculations. J. Solid State Chem. 1997, 128, 197-204.

(13) Viennois, R.; Niedziolka, K.; Jund, P. Physical Properties of the Thermoelectric Cubic Lanthanum Chalcogenides La ${ }_{\mathrm{y}} \mathrm{X}_{4}(\mathrm{X}=\mathrm{S}$, Se, Te) from First Principles. Phys. Rev. B 2013, 88, 174302.

(14) Li, P.; Li, H.; Jie, W. Preparation of Lanthanum Sulfide Nanoparticles by Thermal Decomposition of Lanthanum Complex. J. Rare Earths 2011, 29, 317-320.

(15) Takahashi, N.; Gubarevich, A.; Sakurai, J.; Hata, S.; Tsuge, T.; Kitamoto, Y.; Yamazaki, Y.; Odawara, O.; Wada, H. Preparation and Optical Properties of Rare Earth Doped $\mathrm{Y}_{2} \mathrm{O}_{3}$ Nanoparticles Synthesized by Thermal Decomposition with Oleic Acid. Adv. Mater. Res. 2011, 332-334, 1974-1978.

(16) Brown, M. R.; Roots, K. G.; Shand, W. A. Energy Levels of Er ${ }^{3+}$ in LiYF 4 . J. Phys. C Solid State Phys. 1969, 2, 304. 